\title{
Evaluación de medios de cultivo sintéticos y cereales para la producción de semilla de setas comestibles
}

\section{Evaluation of cereals and artificial cultivation methods in the production of spawn of edible mushrooms}

CAROLINA SUÁREZ A. ${ }^{1,3}$ MARTHA STELLA HOLGUÍN H. ${ }^{2}$

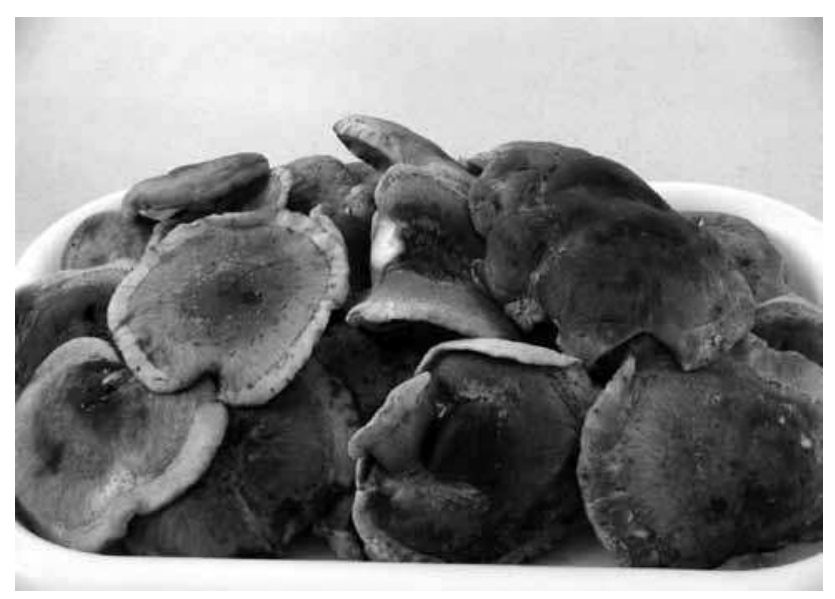

\section{RESUMEN}

Los macromicetos, en especial las setas comestibles, han sido parte de la cultura humana desde hace miles de años como alimento en las más importantes civilizaciones de la historia. Se han descrito muchas propiedades nutracéuticas de estos hongos; tienen un elevado contenido de proteína, poseen todos los aminoácidos esenciales para las funciones humanas, así como un alto contenido de vitaminas y minerales, también poseen propiedades anticancerígenas y antitumorales, hipocolesterolémicas, antivirales, antibacterianas, inmunomoduladoras, entre otras. Pleurotus sp. (orellanas) y Lentinula edodes (Shiitake) se encuentran entre las setas con un mayor índice de producción a nivel mundial. En Colombia, el cultivo de este tipo de hongos es poco generalizado por lo que las fuentes de información para llevar a cabo este tipo de cultivos son reducidas. Se evaluaron diferentes medios de cultivo artificiales y diferentes tipos de semillas de cereales para la producción de micelio y semilla (spawn). Los aislamientos de hongos fueron sembrados en cajas de Petri que contenían los diferentes medios de cultivo y su crecimiento fue medido cada dos días; las semillas de cereal fueron inoculadas con las cepas y su crecimiento se determinó cualitativamente. El mejor medio para la producción de micelio fue PDA (papa, dextrosa y agar) con una tasa de crecimiento específica de $0,80 \mathrm{~mm} \mathrm{día}^{-1}$ para $L$. edodes, 0,81 para $P$. pulmonarius y 0,65 para $P$. ostreatus. El mejor cereal para la producción de semilla fue el trigo, de acuerdo con la escala realizada para este trabajo.

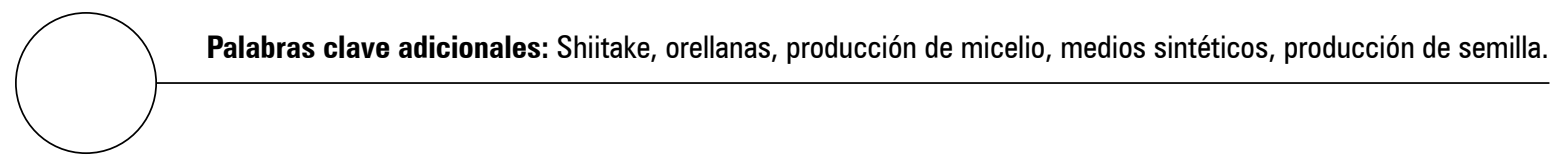

\footnotetext{
Programa de Maestría en Ciencia y Tecnología de Alimentos, Instituto de Ciencia y Tecnología de Alimentos (ICTA), Universidad Nacional de Colombia, Bogotá (Colombia).

2 Instituto de Ciencia y Tecnología de Alimentos (ICTA), Universidad Nacional de Colombia, Bogotá (Colombia).

3 Autor para correspondencia.csuareza@unal.edu.co
} 


\section{ABSTRACT}

Macromycetes, especially edible mushrooms, have been part of human culture for thousands of years as a food in the most important civilizations throughout history. Many nutraceutical properties of mushrooms have been described, they have a high protein content, equal to or higher than some vegetables, they have all the essential amino acids for human functions and a high content of vitamins and minerals; they also have medicinal properties such as anticancer, antitumor, hypocholesterolemic, antiviral, antibacterial, and immunomodulatory effects, among others. Pleurotus sp. (oyster mushrooms) and Lentinula edodes (Shiitake) are among the mushrooms with the highest rate of production worldwide. In Colombia, cultivation of these fungi is not widespread due to a lack of information on local production. Several artificial cultivation methods and cereal seeds were evaluated for the production of mycelium and seed (spawn). Isolated strains were grown in Petri dishes with different media and their growth was measured every two days, cereals seeds were inoculated and their infection level was measured qualitatively. The best media was PDA (potato, dextrose, agar) with a specific growth rate $\left(\mathrm{mm} \mathrm{day}^{-1}\right)$ of 0.80 for L. edodes, 0.81 for P. pulmonarius and 0.65 for $P$. ostreatus. The best grain for spawn production on the scale of this study was wheat.

Additional key words: Shiitake, oyster mushroom, mycelia production, synthetic media, spawn production.

Fecha de recepción: 24-03-2011

Aprobado para publicación: 27-05-2011
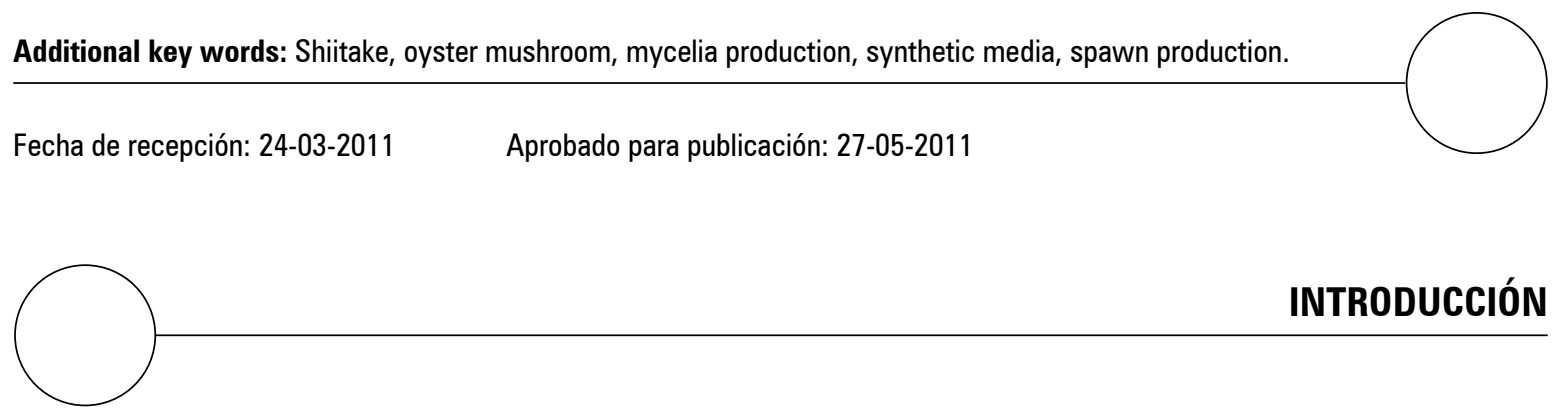

INTRODUCCIÓN

El reino fungi comprende un inmenso grupo de organismos muy versátiles, con diferentes morfologías, fisiologías, ciclos de vida, entre otros; son descritos como organismos unicelulares o pluricelulares, eucarióticos, productores de esporas, que carecen de clorofila, heterótrofos, que se reproducen tanto sexual como asexualmente y que usualmente son filamentosos, ramificados con estructuras somáticas llamadas hifas y típicamente rodeados de paredes celulares (Alexopolus et al., 1996). En este reino se incluyen los phylum Chytridiomycota, Zygomycota, Glomeromycota, Ascomycota y Basidiomycota como los principales, así como el grupo de fungi imperfecti u hongos amorfos (Ainsworth et al., 2001). Aparte de la clasificación taxonómica oficial de los hongos, existen otras, en las que se incluye la que los diferencia por el tamaño de sus órganos de reproducción sexual, es decir si estos pueden ser observados a simple vista y pueden ser colectados con la mano; de acuerdo con esto son divididos en micromicetos y macromicetos. Los macromicetos han sido parte de la humanidad desde hace miles de años y se han descrito como alimento humano en las más importantes civilizaciones de la historia (Smith et al., 2002). Desde la década de los setenta se han incrementado las investigaciones científicas en este tipo de organismos debido a sus propiedades medicinales y al legado cultural que se tienen de ellos, en especial en el Lejano Oriente. Debido a esto, se han descrito muchas propiedades nutracéuticas de los macrohongos (macromicetos), como son: anticancerígenas y antitumorales, hipocolesterolémicas, antivirales, antibacterianas, inmunomoduladoras, entre otras (Mattila et al., 2000; Smith et al., 2002). Igualmente, han sido descritas sus propiedades nutricionales; tienen un elevado contenido de proteína (casi igual o superior al de algunas legumbres) lo que los hace un gran sustituto de la carne cuando la dieta no incluye mucha proteína animal; además, poseen 
todos los aminoácidos esenciales para las funciones humanas, así como un alto contenido de vitaminas y minerales (Caglarirmak, 2007; MushWorld, 2004). Los géneros Pleurotus y Lentinula se encuentran entre los primeros en producción mundial, los principales productores de estos hongos se encuentran en el lejano oriente y Estados Unidos; en Latinoamérica, Chile es el mayor productor de setas mientras que Colombia ocupa el tercer lugar, después de Argentina (Díaz y Ortiz, 2001; Guarín y Ramírez, 2004).

En Colombia, el cultivo de este tipo de hongos está destinado a estratos socioeconómicos altos, debido a que la oferta en el país es muy baja y sus precios son muy elevados. Los agricultores colombianos no poseen las herramientas básicas para producirlos debido a que las fuentes de información acerca de este tipo de cultivos son en idiomas diferentes al castellano y además, la investigación en el país sobre este tipo de organismos es reducida. Uno de los mayores problemas que tienen los productores de este tipo de hongos es su procedencia asiática y por consiguiente se debe importar la cepa para producirla; lo que acarrea costos elevados y por consiguiente, el costo de producción se aumenta, llevando también ese costo a los consumidores (Villegas et al., 2007).

El uso de cepas no foráneas, es decir, cepas aclimatadas a condiciones locales, hace que los productores tengan una ventaja, la producción de las setas se da en un menor tiempo que si se usa una cepa recién traída del exterior (Torres y Hurtado, 2003). El tener la capacidad de reproducir este tipo de organismos por los cultivadores colombianos y en ambientes autóctonos hace que la rentabilidad del negocio sea mucho mayor y que muchos más cultivos se instalen a lo largo del país; lo que conllevaría a más puestos de trabajo y mejoras en las capacidades socioeconómicas de un tipo de población muy especial en el país, la de desplazados, que es uno de los tipos de población objetivo para que desarrollen este tipo de cultivos (Arias et al., 2008; MushWorld, 2005).
El objetivo de esta investigación fue evaluar in vitro medios de cultivo artificiales comerciales $y$ de semillas de cereal comunes para la producción de micelio y, posteriormente, de la semilla (spawn) para que productores de este tipo de alimentos puedan producir sus propios insumos y así disminuir los costos de producción; llevando a un gran impulso en la producción de este tipo de macromicetos lo que generaría muchas más fuentes de empleo, mayores ingresos de los productores $y$ por consiguiente una mayor oferta al consumidor, que se beneficiaría de un menor precio por un producto que además de nutrirle, le llevaría grandes beneficios en su salud.

\section{MATERIALES Y MÉTODOS}

\section{Materiales}

Los cuerpos fructíferos maduros y no esporulados de Pleurotus ostreatus, Pleurotus pulmonarius y Lentinula edodes, se obtuvieron de un proveedor local. Se determinó con este proveedor el estado de maduración, tamaño y fechas destinadas para el análisis y desarrollo del proyecto, para esto, se hizo un cronograma de siembras que permitieron la obtención de carpóforos de primera o segunda oleada (cosecha) ya que hay menos peligro de contaminación y las cepas no han tenido el tiempo de perder sus propiedades características, como ocurre cuando los cultivos son muy viejos (Scrase, 1995; Stamets y Chilton, 1983).

Los medios de cultivo específicos para evaluar el crecimiento del micelio fueron: PDA (papa, dextrosa y agar) Oxoid $₫$, OGY (oxytetraciclina, extracto de levadura y glucosa) Oxoid® y Sabouraud Difco®. Para la prueba de confirmación de la viabilidad del micelio que se obtuvo, se evaluaron diferentes tipos de cereales (maíz amarillo, cebada, trigo, millo y sorgo) para producir semilla, las semillas utilizadas fueron adquiridas en un mercado local, todas pertenecientes a un mismo lote. 


\section{Metodología}

Para el aislamiento del micelio se tomó el carpóforo y se cortaron con un escalpelo estéril y en un ambiente estéril, pequeños cuadrados de $4 \mathrm{~mm}$ de lado. Los trozos se dispusieron en una caja de Petri estéril y se desinfectaron así: tres lavados con hipoclorito de sodio al 3\%, por un minuto con un enjuague entre cada lavado con agua destilada estéril un minuto, posteriormente, se hizo un lavado con alcohol al $70 \%$ durante un minuto y posterior lavado con agua destilada estéril por otro minuto.

Luego de tener los trozos desinfectados, se sembraron en superficie en agar PDA, cinco o seis trozos fueron puestos de forma radial en las placas con una separación tal que las hifas tuvieran suficiente espacio para crecer. Las cajas fueron incubadas a $22 \pm 2^{\circ} \mathrm{C}$, por $5 \mathrm{~d}$ o hasta que las mismas fueron cubiertas completamente por el micelio.

Después de tener micelio completamente puro, se procedió a la evaluación de los diferentes medios de cultivos para determinar cuál de ellos es mejor para el aislamiento y producción de micelio. Los medios de cultivo fueron reconstituidos de acuerdo con el fabricante y esterilizados a $121^{\circ} \mathrm{C}$ durante $15 \mathrm{~min}$; después se sirvieron en cajas de Petri de vidrio y se dejaron solidificar. Con escalpelo estéril se cortaron trozos de agar con micelio de $4 \mathrm{~mm}$ de lado y se sembraron centralmente para poder medir el radio de crecimiento del micelio en el tiempo. Las cajas se incubaron a $22 \pm 2{ }^{\circ} \mathrm{C}$ hasta que el micelio cubriera toda la superficie del agar. El radio de crecimiento fue medido con un calibrador (Mitutoyo ${ }^{\circledR}$ ) cada dos días y reportado en milímetros. Se realizaron cinco réplicas para cada medio de cultivo y especie de hongo.

Después de tener el micelio puro en las cajas de Petri, se evaluaron los granos de cereal. El procedimiento para producir la semilla, es descrito por Saldarriaga (2001). Se tomaron los granos de cereal y se lavaron con abundante agua, eliminando los granos infectados o rotos, además de los desechos vegetales que quedan después de la recolección de los cereales (ramas, hojas, tallos, etc). Se dejaron en agua por una noche para que los granos se hidrataran y luego, se escurrieron. Se adicionó un 1\% (en base húmeda) de carbonato de calcio a los granos de cereal y posteriormente, se esterilizaron a $121^{\circ} \mathrm{C}$ y $15 \mathrm{lb}$ de presión por $1 \mathrm{~h}$, debe cumplirse el tiempo de esterilización ya que si esto no se da, el porcentaje de contaminación por mohos, especialmente Trichoderma spp., se incrementa. Se midió el porcentaje de humedad y el pH de los granos después de la esterilización. El promedio de pH fue 5,96 y el de humedad 46,3\%.

Después de que los frascos con los granos estuvieron a temperatura ambiente, se inocularon. Se tomaron cuadrados de agar de $1 \mathrm{~cm}$ de lado $y$ se distribuyeron en el frasco que contiene los granos, entre tres y cuatro cuadrados de agar son suficientes para que haya una rápida y efectiva infección de los granos. Se incubaron en oscuridad a $22 \pm 2^{\circ} \mathrm{C}$ por el tiempo que fuera necesario hasta que se observara una infección completa de los granos, a la semana de incubación, los frascos se agitaron para que hubiera una distribución homogénea del micelio y de humedad.

El crecimiento del micelio fue medido cualitativamente en el tiempo, se observaba la distribución y abundancia de micelio en los granos de cereal. Se determinó el final de la incubación cuando el frasco tenía un color blanco debido al crecimiento abundante del micelio.

\section{Diseño experimental}

Se utilizó un arreglo de $3 \times 3$, con un diseño de bloques al azar, con tres tipos de aislamiento y en tres tipos de medios de cultivo; se hicieron cinco repeticiones por tratamiento (135 muestras analizadas), de manera que se pudieron evaluar las diferencias entre tratamientos y especies mediante un análisis de varianza (Anova); rea- 
lizando la prueba de Fischer (5\%). El análisis de los datos se llevó a cabo empleando el software el SPSS 17® para Windows ${ }^{\circledR}$.

\section{RESULTADOS Y DISCUSIÓN}

\section{Evaluación de medios de cultivo para produc- ción de micelio}

Para todas las cepas, se observó que el medio de cultivo más rápidamente invadido fue PDA, $L$. edodes y $P$. pulmonarius fueron las cepas que tuvieron un crecimiento más rápido en este medio, invadiendo la caja en $8 \mathrm{~d}$, mientras que $P$. ostreatus tuvo un crecimiento más lento en este tipo de agar. El segundo medio de cultivo más rápido fue OGY, mientras que Saboureaud tuvo un pobre crecimiento, a tal punto que el crecimiento micelial se detuvo en un momento determinado.

Al realizar un análisis cualitativo de los resultados se pudo observar que hay diferencias entre los medios y las cepas empleadas. Cada cepa tuvo un comportamiento distinto entre los diferentes medios de cultivos y como era de suponerse, el comportamiento de cada cepa fue diferente comparado con otra. Esto se corrobora con el análisis estadístico de los datos, la prueba de Fischer indicó con un porcentaje de confianza del 95\% $(P<0,05)$ que hubo diferencias significativas entre los diferentes medios de cultivo y diferencias entre las cepas empleadas. Los promedios de los resultados de crecimiento del micelio de acuerdo a la cepa y al agar se presentan en la tabla 1.

Ningún medio de cultivo tuvo un comportamiento diferente para una cepa determinada, los tres medios de cultivo tuvieron un comportamiento similar para los tres hongos estudiados, lo que indica que esto podría extrapolarse a la totalidad de hongos de este tipo, es decir, los hongos de la pudrición blanca de la madera, ya que se estudiaron dos géneros que comparten esta característica (ligninolíticos y celulolíticos) pero que no tienen la misma clasificación taxonómica. El micelio obtenido es característico de cada especie, mientras que para L. edodes (Shiitake) el micelio es poco denso, simétrico y podría describirse "débil"; para las orellanas $(P$. pulmonarius y $P$. ostreatus) se observó un micelio denso, de crecimiento irregular, abundante y "fuerte"; sin que los adjetivos "débil" y "fuerte" tengan que ver con su índice de infección en los medios de cultivo o los granos de cereal. La tabla 1 demuestra que a pesar de que el Shiitake tuvo

Tabla 1. Crecimiento radial $(\mathrm{mm})$ de Pleurotus ostreatus, Pleurotus pulmonarius y Lentinula edodes en diferentes tipos de medio de cultivo.

\begin{tabular}{|c|c|c|c|c|c|c|c|c|}
\hline \multirow[b]{2}{*}{ Aislamientos } & \multirow[b]{2}{*}{ Medios de cultivo } & \multicolumn{7}{|c|}{ Tiempo (días) } \\
\hline & & 2 & 4 & 6 & 8 & 10 & 12 & 14 \\
\hline \multirow{3}{*}{ L. edodes } & PDA & 3,0 & 11,8 & 31,0 & 44,4 & & & \\
\hline & OGY & 0,4 & 10,8 & 17,2 & 25,6 & 38,8 & 45,0 & \\
\hline & Sabouraud & 0,3 & 7,0 & 13,4 & 19,2 & 29,6 & 39,6 & \\
\hline \multirow{3}{*}{ P. pulmonarius } & PDA & 3,0 & 10,4 & 36,8 & 45,0 & & & \\
\hline & $\mathrm{OGY}$ & 3,0 & 11,6 & 20,6 & 31,6 & 45,0 & & \\
\hline & Sabouraud & 1,2 & 6,2 & 11,2 & 17,8 & 27,2 & & \\
\hline \multirow{3}{*}{ P. ostreatus } & PDA & 2,6 & 7,2 & 23,4 & 37,4 & 45,0 & & \\
\hline & OGY & 2,8 & 14,2 & 23,6 & 34,4 & 41,6 & 45,0 & \\
\hline & Sabouraud & 1,2 & 4,6 & 7,6 & 11,8 & 16,6 & 24,8 & 33,8 \\
\hline
\end{tabular}


un crecimiento micelial poco denso, su velocidad de crecimiento fue prácticamente igual que para las otras dos especies.

Con los datos obtenidos del crecimiento se determinó hallar la velocidad de crecimiento de las diferentes especies de hongos en los diferentes tipos de agar. Como primera medida se graficaron los datos obtenidos, representados en la tabla 1. Las figuras 1,2 y 3 , representan el crecimiento de los diferentes hongos en los medios de cultivo sintéticos evaluados. Las gráficas muestran que el crecimiento en PDA fue más rápido para todas las cepas, que el segundo mejor medio artificial fue OGY y por último el Sabouraud.

El tipo de crecimiento filamentoso o algodonoso indica cualitativamente la producción de biomasa de las cepas, sin embargo, para determinar cuantitativamente dicha producción se procedió a realizar diferentes cálculos matemáticos con base en la ecuación logística de Velhurst-Pearl, originalmente desarrollada para el crecimiento de una población (Viniegra-González et al., 2003); esta ecuación asume que los cultivos microbianos están prácticamente saturados por el sustrato y por consiguiente, la tasa de crecimien- to específico no es una función de la concentración del sustrato (Viniegra-González et al., 2003). La tabla 2 muestra las ecuaciones obtenidas con los datos experimentales y el respectivo ajuste $\left(R^{2}\right)$.

Como se describió anteriormente, el medio de cultivo sintético que mejor resultado arrojó para el aislamiento y producción de micelio fue PDA. No existen estudios científicos que determinen el porqué de este comportamiento por parte de los hongos, sin embargo este es uno de los medios de cultivo mayormente utilizados para la manutención y preservación de los hongos. En la mayoría de estudios realizados con este tipo de macromicetos, el PDA es el medio de cultivo mayormente utilizado para iniciar la activación de la cepa y su posterior uso, tanto para fermentaciones en estado líquido (FEL), como en trabajos realizados con cultivo tradicional y fermentación en estado sólido (FES) (Feng et al., 2010; Turlo et al., 2010; Osman et al., 2009; Tepwong y Ohshima, 2009). Este medio de cultivo tiene todos los componentes nutritivos para que los hongos se desarrollen, el extracto de papa proporciona almidón, algo de lignina y otros minerales que ayudan a que los hongos se desarrollen

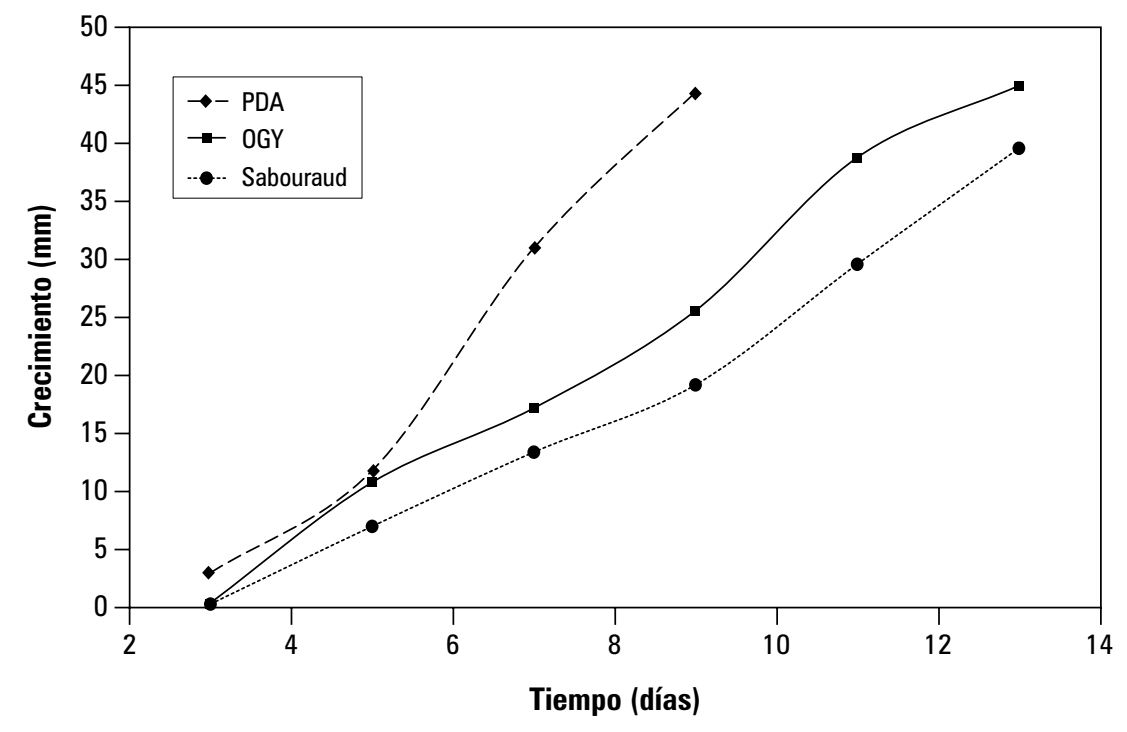

Figura 1. Crecimiento de Lentinula edodes según los medios de cultivo evaluados. 


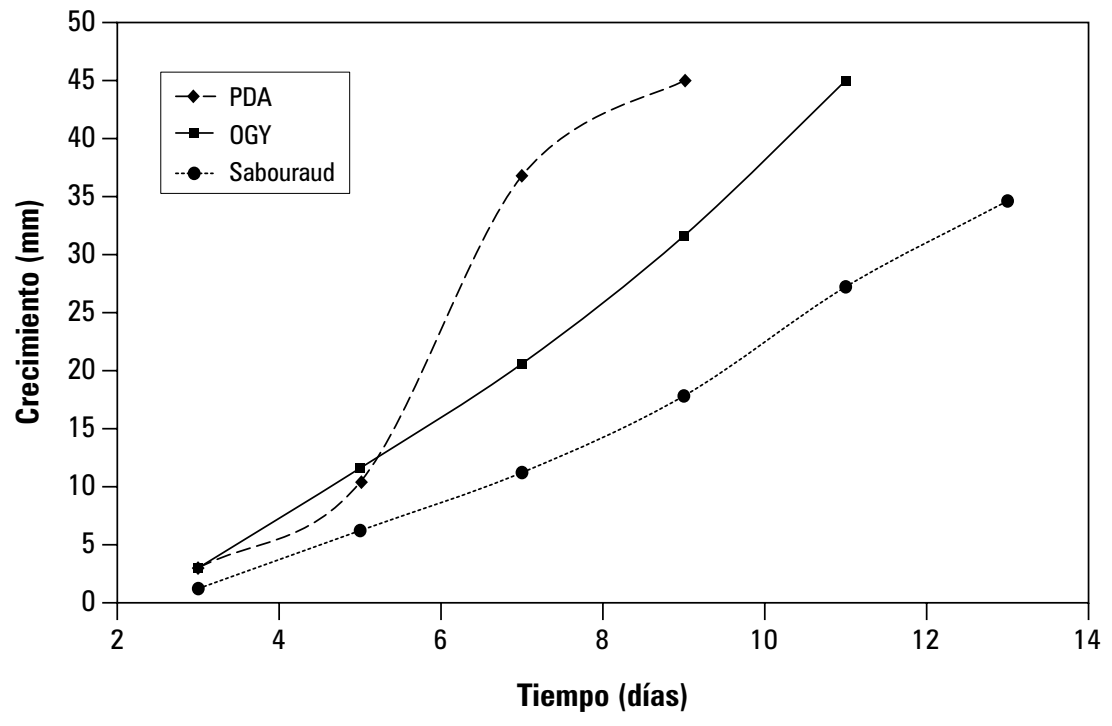

Figura 2. Crecimiento de $P$. pulmonarius según los medios de cultivo evaluados.

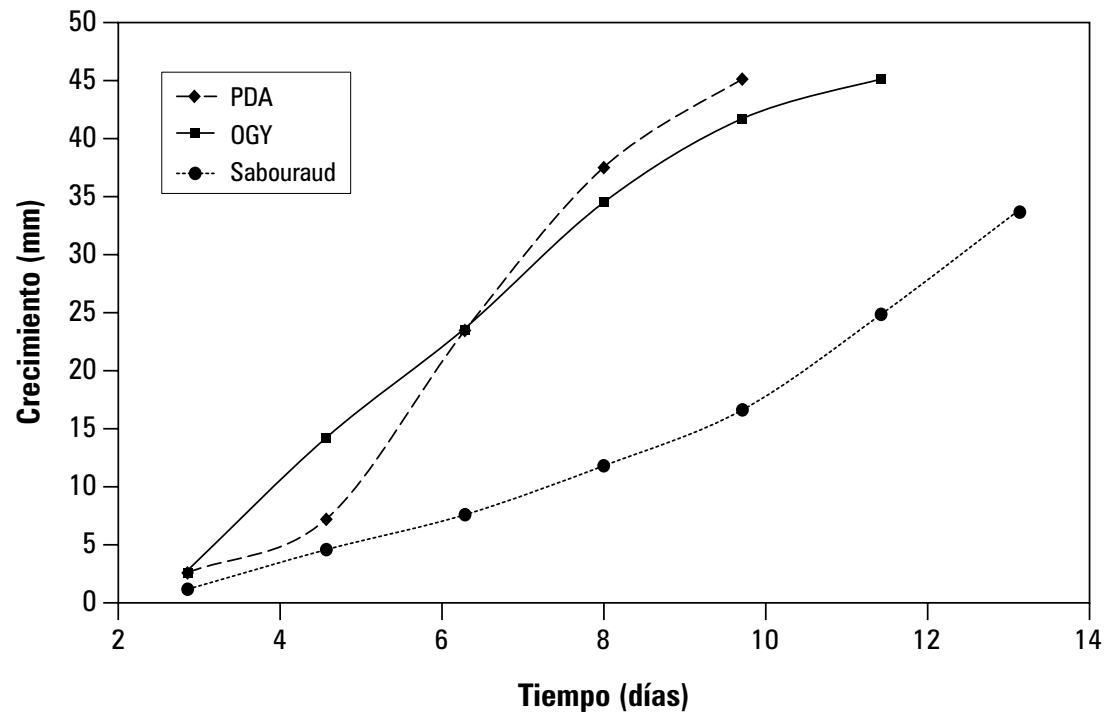

Figura 3. Crecimiento de $P$. ostreatuss según los medios de cultivo evaluados.

e inhiban el crecimiento de bacterias, la dextrosa (glucosa) es la fuente de carbono principal para los hongos y el agar es adicionado como agente gelificante, su pH $(5,6 \pm 2)$ es ideal para el crecimiento de hongos y la inhibición de bacterias debido a su ligera acidez. El medio OGY (extracto de levadura, glucosa y extracto de levadura) tiene en su composición también la glucosa como su principal fuente de carbono, pero contiene además extracto de levadura y como agente antibacteriano la oxitetraciclina, aunque el medio contenga la glucosa, es evidente que el extracto de levadura, que en su mayoría es un componente proteico no brinda las mejores condiciones nutri- 


\begin{tabular}{|c|c|c|c|c|c|c|}
\hline Hongo & PDA & $R^{2}$ & OGY & $R^{2}$ & Sabouraud & $R^{2}$ \\
\hline Lentinula edodes & $y=0,9879 e^{0,8051 x}$ & 0,98 & $y=1,3985 e^{0,5456 x}$ & 0,92 & $y=1,2616 e^{0,5332 x}$ & 0,96 \\
\hline $\begin{array}{l}\text { Pleurotus } \\
\text { pulmonarius }\end{array}$ & $y=0,9659 e^{0,817 x}$ & 0,97 & $y=1,4258 e^{0,6145 x}$ & 0,95 & $y=1,4339 e^{0,4896 x}$ & 0,97 \\
\hline $\begin{array}{l}\text { Pleurotus } \\
\text { ostreatus }\end{array}$ & $y=1,233 e^{0,648 x}$ & 0,96 & $y=1,9369 e^{0,5136 x}$ & 0,88 & $y=1,5982 e^{0,3982 x}$ & 0,98 \\
\hline
\end{tabular}

cionales para el desarrollo de este tipo de hongos (éste es un medio utilizado para el conteo de mohos y levaduras en el control de calidad microbiológico de alimentos), aunque se podría contar como una opción al no tener PDA, ya que el crecimiento es más lento sólo por unos pocos días (2 a 4). El medio Sabouraud fue el que tuvo un resultado menos favorecedor, en todos los casos, el crecimiento micelial de las especies de hongos se detuvo, las cajas se tuvieron en incubación días después que las placas de otros medios fueron retiradas pero en vez de haber crecimiento, el medio se deshidrató, es por eso que los tiempos se detuvieron hasta cuando se sacaron las últimas cajas de los otros agares. Se puede concluir que este medio no es una buena opción para el crecimiento de estos hongos macromicetos, aunque el medio de cultivo contiene también dextrosa, el complemento, que es un concentrado enzimático de caseína, no es el adecuado para la producción de micelio, debido a que es un concentrado proteico y de origen animal, este es un medio que aunque es utilizado para el conteo de hongos en el laboratorio, no es el indicado para hongos de la pudrición de la madera.

El realizar un estudio de la cinética de crecimiento de las especies estudiadas, es importante para el investigador porque se puede entender con mayor profundidad el comportamiento de los microorganismos estudiados y tener una mejor explicación a un cambio de las condiciones de crecimiento de las especies. El punto de partida para estudiar por ejemplo, el crecimiento de un cierto tipo de microorga- nismo bajo un nuevo medio de cultivo, debe ser comparado obligatoriamente con un medio de cultivo ampliamente estudiado y conocido para determinar si este nuevo medio de cultivo es mejor que el utilizado comúnmente. No se han realizado muchos estudios de la cinética de crecimiento de este tipo de hongos en medios sólidos, las investigaciones se han enfocado a la cinética de crecimiento de hongos en fermentaciones líquidas, ya que son en este tipo de fermentaciones en las que se puede determinar con mejor precisión el agotamiento de un nutriente, o la producción de algún metabolito secundario de interés. Sin embargo, es bueno aclarar que la cinética se debe hacer para cada experimento, ya que las condiciones ambientales, especialmente, cambian de un laboratorio a otro, pero podrían ser comparables en un momento determinado y los datos serían de gran utilidad e importancia.

La cinética de crecimiento estudiada en este trabajo hace pensar que el comportamiento de las cepas in vitro es similar en cuanto a los medios de cultivo utilizados. Se hallaron las ecuaciones de crecimiento que permitieran describir el crecimiento de las diferentes especies de hongos. El coeficiente de determinación $\left(R^{2}\right)$ indicó que los datos obtenidos no tienen una gran variación entre sí y que se ajustan en gran medida a la ecuación propuesta. El hongo con una tasa de crecimiento específica menor fue $P$. ostreatus para todos los medios de cultivo, mientras que para PDA, $P$. pulmonarius y $L$. edodes este índice fue similar, para OGY y Sa- 
bouraud se ven diferencias y P. pulmonarius tuvo una tasa mayor para estos medios que L. edodes.

\section{Evaluación de cereales}

El crecimiento del micelio fue medido cualitativamente en el tiempo, se observaba la distribución y abundancia de micelio en los granos de cereal. Se determinó el final de la incubación cuando el frasco tenía un color blanco debido al crecimiento abundante del micelio.

Según los resultados obtenidos se puede concluir que el trigo es el mejor cereal para la producción de semilla (spawn) en todos los géneros de hongos. Se dio una rápida y homogénea infección de los granos. En dos semanas, los frascos fueron completamente infectados y el micelio era denso. La cebada fue el segundo mejor cereal, aunque el crecimiento fue mucho más lento que para el trigo (3 semanas), se dio de manera uniforme en los granos y para las tres cepas de hongos. Hubo diferencias entre ciertos tipos de cereal, mientras que el trigo fue una excelente semilla para la producción de spawn para todas las cepas, el sorgo fue mejor para L. edodes, que para las dos cepas de Pleurotus; este resultado concuerda con lo reportado por García (2003), quien usó esta misma semilla de cereal para desarrollar su investigación sobre el crecimiento de L. edodes en diferentes sustratos. El millo y el maíz amarillo no tuvieron una buena infección por parte del micelio de los hongos, para que se viera la infección de los granos se debió esperar más de 4 semanas y para ver una infección total del cereal se debió esperar más de 6 semanas. La tabla 3, describe el comportamiento de los diferentes granos de cereal, en cuanto a la infección del micelio de los hongos.

Para la preparación de la semilla es primordial los pasos anteriores a la inoculación de los granos. El grano debe estar sumergido en agua entre 16 y 24 h para que absorba toda el agua posible y pueda haber una buena infección del grano (cuanto más húmedo, más susceptible a la infección) y además, para que existan las condiciones de humedad propias para el desarrollo del hongo. Debe existir la proporción perfecta de carbonato de calcio y el peso en base húmeda de los granos, ya que si se adiciona más carbonato el $\mathrm{pH}$ puede aumentar más de lo recomendable $(5,5)$ (Stamets, 1993) o si no se agrega la cantidad suficiente el $\mathrm{pH}$ permitiría la aparición de bacterias que inhibirían el crecimiento del hongo si el proceso de esterilización no es el adecuado. Es necesario asegurarse que la temperatura en el centro térmico de los granos sea superior a los $121{ }^{\circ} \mathrm{C}$ (temperatura de esterilización) ya que se puede dar el caso de que los granos ubicados en el centro del frasco tengan focos de contaminación, en especial de mohos, que compitan con el hongo a producir y sea inhibido. Si se presenta un foco de contaminación visible ya que por lo general este tipo de mohos poseen un color verde, pardo, gris, o negro, el frasco debe ser esterilizado nuevamente y el proceso de limpieza y desinfección debe darse nuevamente, o simplemente los granos son eliminados.

Tabla 3. Evaluación del crecimiento micelial en granos de cereal.

\begin{tabular}{|l|c|c|c|c|c|} 
& Trigo & Sorgo & Cebada & Millo & Maíz amarillo \\
\hline P. ostreatus & +++ & + & ++ & + & + \\
\hline P. pulmonarius & +++ & + & ++ & + & + \\
\hline L. edodes & +++ & ++ & ++ & + & + \\
\hline
\end{tabular}

Escala: +++ Alto porcentaje de infección, crecimiento rápido; + + Porcentaje de infección medio, crecimiento lento; + Poco porcentaje de infección, crecimiento lento. 
En cuanto a la evaluación de los granos de cereal, aunque no se hizo un análisis cuantitativo, se puede concluir que el mejor grano es el trigo, seguido por la cebada, el sorgo, el millo y el maíz amarillo. Esto concuerda con Stamets (1993) quien dice que los mejores cereales son el trigo, la cebada y el sorgo. Esto se da por la cantidad de agua que los granos pueden absorber y también al contenido de almidones de fácil rompimiento, contenido de lignina, celulosa, etc. El millo y el maíz son granos muy duros que el hongo no puede penetrar. Para que puedan ser más fáciles de penetrar, los granos deberían tener un menor grado de madurez, pero esto implica que todos los almidones y azúcares presentes en el grano no estén en una concentración óptima y entonces el hongo no se desarrollaría por falta de nutrientes. Si es necesario usar este tipo de cereales se recomienda sumergirlos en agua por un periodo más largo, para que las paredes del grano se ablanden más y el hongo pueda penetrarlas.

\section{CONCLUSIONES}

Los medios de cultivo sintéticos comerciales son las herramientas primordiales para el estudio de microorganismos, sabiendo cuál es el mejor de ellos para un tipo de microorganismo, se puede inferir su metabolismo y así, empezar a realizar variaciones en este medio para optimizar aún más el crecimiento del microorganismo. En el caso de los hongos de la pudrición blanca se pudo concluir que el medio sintético PDA (papa, dextrosa y agar), fue el que permitió un mayor desarrollo y crecimiento rápido del micelio de $P$. ostreatus, $P$. pulmonarius y L. edodes, esto con el fin de obtener micelio puro y rápidamente para la preparación de la semilla. En cuanto a la producción de semilla (spawn), el mejor cereal para su producción fue el trigo, seguido de la cebada, el sorgo, el millo y el maíz amarillo, es necesario realizar estudios cuantitativos y de cinética de crecimiento de este tipo de hongos en los cereales para obtener datos más precisos.

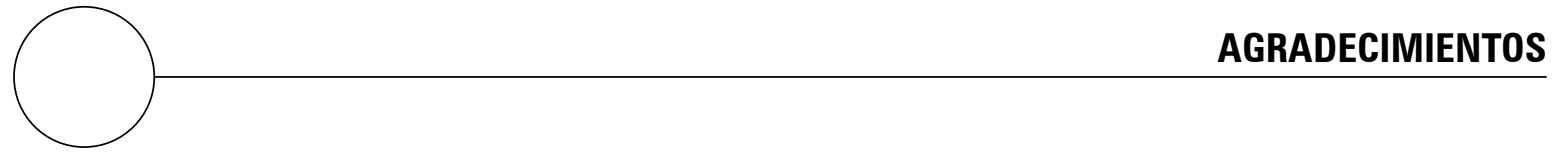

Los autores expresan sus agradecimientos al Posgrado en Ciencia y Tecnología de Alimentos de la Universidad Nacional de Colombia, sede Bogotá y a su director Néstor Algecira, por cofinanciar el desarrollo de este proyecto.

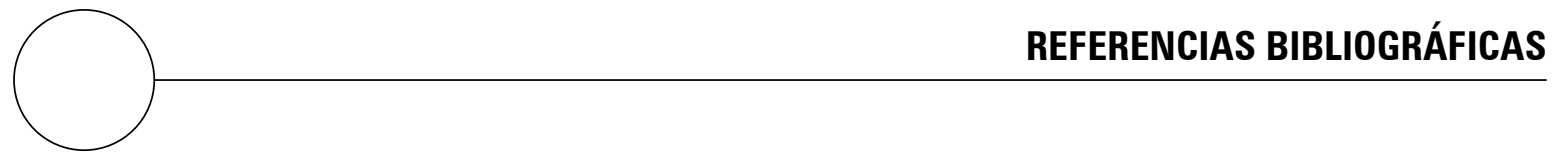

Ainsworth, G.C., P.M. Kirk, G.R. Bisby, P.F. Cannon, J.C. David y J.A. Stalpers. 2001. Ainsworth \& Bisby's Dictionary of the fungi. $9^{\text {th }} \mathrm{ed}$. Cabi Publishing, Cambridge, UK.

Alexopolus, C.J., C.W. Mimsy y M. Blackwell. 1996. Introductory mycology. $4^{\text {th }}$ ed. John Wiley \& Sons, New York, NY.

Arias, G., C. Gutiérrez y C. Ospina. 2008. Propuesta del cultivo de hongo Pleurotus y Lentinula edodes a partir de la biomasa del café en las fincas cafeteras de Manizales para el fortalecimiento de los programas de desarrollo alternativo. Cuadernos Latinoamericanos de Administración 4(6), 35-68.

Caglarirmak, N. 2007. The nutrients of exotic mushrooms (Lentinula edodes and Pleurotus species) and an estimated approach to the volatile compounds. Food Chem. 105, 11881194. 
Díaz, J.A. y F. Ortiz. 2001. Mercado internacional de hongos exóticos. Biocomercio sostenible. Instituto Alexander von Humboldt, Bogotá.

Feng, Y., W. Li, X. Wu, J. Cheng y S. Ma. 2010. Statistical optimization of media form mycelia growth and exopolysaccharide production by Lentinus edodes and a kinetic model study of two morphologies. Biochem. Eng. J. 49, 104-112.

García, I. 2003. Experimentación de diferentes tipos de sustratos para el cultivo de Lentinus edodes (Shiitake) y su desarrollo químico-biológico. Universidad Autónoma Metropolitana de Iztapalapa, Iztapalapa, México.

Guarín, J.A. y A. Ramírez. 2004. Estudio de la factibilidad técnico-financiera de un cultivo del hongo Pleurotus ostreatus. Pontificia Universidad Javeriana, Bogotá.

Mattila, P., K. Suonpää y V. Piironen. 2000. Functional properties of edible mushrooms. Nutrition16 (7/8), 694- 696.

MushWorld. 2004. Mushroom growers handbook. 1. Oyster mushroom cultivation. MushWorld, Heineart Inc., Seoul, Korea.

MushWorld. 2005. Mushroom growers handbook. 2. shiitake cultivation. MushWorld, Heineart Inc., Seoul, Korea.

Osman, M., F. Hassan, O. Khattab, W. Ahmed y H. ElHenawy. 2009. Physiological studies on growth of two differ strains of Lentinus edodes. Aust. J. Basic Appl. Sci. 3, 4094-4103.

Saldarriaga, Y. 2001. Manual de micología aplicada. Universidad de Antioquia, Medellín, Colombia. pp. 22-26.

Scrase, R. 1995. Cultivating mushrooms - from pure culture to spawn production. Mycologist 9(2), 53-56.
Stamets, P. 1993. Growing gourmet and medicinal mushrooms. Ten Speed Press, Hong Kong.

Stamets, P. y J. Chilton. 1983. The mushrooms cultivator: a practical guide to growing mushrooms at home. Agarikon Press Olimpia, New York, NY.

Smith, J., N. Rowan y R. Sullivan. 2002. Medicinal mushrooms: their therapeutic properties and current medical usage with special emphasis on cancer treatments. University of Strathclyde, UK.

Tepwong, P. y T. Ohshima. 2009. Biosynthesis of ergothioneine during different stages of submerged fermentation of "shiitake" (Lentinus edodes) mushrooms and their bioactive properties. J. Biosci. Bioeng. 108, 54-55.

Torres, M.G. y A. Hurtado. 2003. Potencial de la micobiota nativa y medicinal en el municipio de Quibdó. Grupo de Investigación en Recursos Vegetales, Universidad Tecnológica del Chocó, Quibdó, Colombia.

Turlo, J., B. Gutkowska y F. Herold. 2010. Effect of selenium enrichment on antioxidant activities and chemical composition of Lentinula edodes (Berk.) Pegl. Mycelia extracts. Food Chem. Toxicol. 48, 1085-1091.

Villegas, V., A.M. Pérez y C. Arreondo. 2007. Evaluación del crecimiento de Lentinula edodes en medios de cultivos sólidos para la producción de micelio como inóculo. Rev. Colomb. Biotecnol. 9(2), 56-63.

Viniegra-González, G., E. Favela-Torres, C. Aguilar, S. Rómero-Gomez, G. Díaz-Godinez y C. Augur. 2003. Advantages of fungal enzyme production in solid state over liquid fermentation systems. Biochem. Eng J. 13, 157-167. 